\title{
Éthiopie. Polyphonies Ari
}

Enregistrements, texte et photographies: Thierry Fournel, 2002

\section{Olivier Tourny}

\section{(2) OpenEdition}

Journals

Édition électronique

URL : http://journals.openedition.org/ethnomusicologie/556

ISSN : 2235-7688

\section{Éditeur}

ADEM - Ateliers d'ethnomusicologie

\section{Édition imprimée}

Date de publication : 1 janvier 2004

Pagination : 384-385

ISBN : 2-8257-0910-7

ISSN : 1662-372X

Référence électronique

Olivier Tourny, «Éthiopie. Polyphonies Ari », Cahiers d'ethnomusicologie [En ligne], 17 | 2004, mis en ligne le 13 janvier 2012, consulté le 22 avril 2019. URL : http://journals.openedition.org/ ethnomusicologie/556

Ce document a été généré automatiquement le 22 avril 2019

Tous droits réservés 


\title{
Éthiopie. Polyphonies Ari
}

Enregistrements, texte et photographies: Thierry Fournel, 2002

\author{
Olivier Tourny
}

\section{RÉFÉRENCE}

Éthiopie. Polyphonies Ari. Enregistrements, texte et photographies: Thierry Fournel. 1 CD Ocora C 560174, 2002

1 Il s'agit là du premier opus d'une série de disques à paraître consacrée à l'Éthiopie, réalisée dans le cadre du programme de Coopération scientifique franco-éthiopien en ethnomusicologie (Ministères éthiopiens de la culture et de l'éducation, Ministère français des affaires étrangères, CNRS-LMS UMR 8099).

2 Cette publication vient témoigner de plusieurs missions d'investigations effectuées par l'auteur dans le sud-ouest éthiopien entre 1999 et 2002. Elle s'inscrit dans le prolongement d'un mémoire de Maîtrise consacré aux Polyphonies vocales et instrumentales Ari, sous la direction de Vincent Dehoux, (Univ. Paris X, septembre 2001).

Les Ari? Une population d'agriculteurs sédentaires, de tradition animiste, qui constitue l'un des groupes les plus nombreux de la mythique vallée de l'Omo. Annexé par l'Éthiopie chrétienne amhara en 1890, leur territoire s'étend sur des hauts-plateaux situés entre 800 et 3000 mètres d'altitude. Mais une population qui reste très hiérarchisée et qui, en dépit des pressions exercées aujourd'hui par les missions protestantes étrangères, préserve encore son identité. Ce qui passe, on s'en doute, par le maintien des pratiques, des rites et des musiques qui leur sont associées.

Et quelles musiques! Et quel bonheur de découvrir, à chaque publication inédite, les corrélations entre une société, sa langue et sa musique. Ainsi, la cérémonie des funérailles se nomme efi, c'est-à-dire "pleurer», tandis que celle qui marque, une ou deux années après, la fin du deuil s'intitule chi:chi, «nettoyer». Ainsi également la polyphonie alla, qui 
signifie « liane», au cours de laquelle les voix des femmes «s'enroulent» autour de celles des hommes.

5 Le disque donne à entendre alternativement deux atmosphères musicales radicalement différentes: l'une, communautaire, qui met en présence des dizaines, voire des centaines de chanteurs, chanteuses, musiciens et danseurs réunis à l'occasion des grandes cérémonies qui marquent la fin des saisons des pluies; l'autre, beaucoup plus intimiste qui ne nécessite que peu de personnes, voire un seul instrumentiste.

Dans le premier cas de figure, les combinaisons polyphoniques sont aussi variées que possible, associant ou non les voix des hommes à celles des femmes, les chœurs mixtes avec un ensemble de flûtes en bambou, le tout le plus souvent accompagné par la danse, le battement des pieds sur le sol, le frappement rythmé des mains, les ioulements et les cris spontanés. La technique prédominante est le hoquet - qu'il soit vocal ou instrumental - mais elle cohabite fréquemment avec d'autres, qu'il s'agisse de refrains ou de motifs mélodiques répétitifs assumés par une partie de l'ensemble. Quant aux instants plus intimes qui jalonnent le disque, ils sont joués à la lyre shungi à cinq cordes - parfois accompagnés par le chant - ou à la flûte shungul. Or, dans les pièces où le jeu instrumental est purement monodique, on serait en droit de se demander ce qu'elles font dans un disque consacré à des musiques polyphoniques. Mais Thierry Fournel en justifie la présence en précisant que ces mélodies instrumentales reprennent et reproduisent la technique du hoquet, « ce qui montre qu'il y a bien une conception horizontale des chants polyphoniques dont on peut extraire une mélodie». Et à la charnière entre les deux se trouve la pièce dénommée anipuq (plage 11), dans laquelle deux petits bergers sifflent dans leur main, chacun leur tour, puis ensemble; de la dialogie à la polyphonie: une merveille!

7 On l'aura compris, ce disque-là est à retenir et ce n'est pas les quelques imprécisions du livret ou les va-et-vient imposés par la facture de ce dernier qui terniront notre enthousiasme. Car ce que l'on retiendra de ces polyphonies ari, en dehors de leur beauté, c'est ce mélange de rigueur et de fraîcheur, de technique et d'imprévu, de raffinement et de simplicité qui transparaît au fil de l'écoute: une musique vivante. Et c'est tout ce qu'on aime. 